\title{
OCORRÊNCIA DE PARASITAS INTESTINAIS COM POTENCIAL ZOONÓTICO EM AMOSTRAS FECAIS DE CÃES, COLETADAS EM PRAÇAS PÚBLICAS DO MUNICÍPIO DE ITUVERAVA, SP, BRASIL
}

DE PAULA, Cleber Jacob Silva ${ }^{1}$ GONTIJO, Laís Silva² SANTOS, Romeu Moreira dos ${ }^{3}$

\begin{abstract}
RESUMO: Em várias cidades do país, numerosa população canina circula livremente pelas ruas e praças públicas, alguns deles levados pelos proprietários. Nesses locais, os cães podem defecar, contaminando o solo com vários tipos e formas de parasitas potencialmente causadores de zoonoses. Atualmente existe uma preocupação muito grande com relação a estes parasitas, devido ao contato cada vez mais próximo de pessoas com seus animais de estimação. O objetivo do presente trabalho foi verificar a ocorrência dos principais parasitas intestinais com potencial zoonótico em amostras fecais de cães, coletadas em praças públicas do município de Ituverava-SP. Foram coletadas 84 amostras frescas de fezes de cães em sete praças públicas de Ituverava-SP, no período de março a junho de 2009. Como método de análise das amostras fecais utilizou-se a técnica de Willis-Mollay (flutuação fecal). No total de amostras analisadas 49 foram negativas e 35 positivas para presença de ovos de helmintos, observando uma maior incidência de ovos de Ancylostoma sp. (29 amostras) e em menores números ovos de Toxocara sp. (4 amostras) e Dipilidium sp. (2 amostras), não sendo ainda encontrados em nenhuma das amostras ovos de Giárdia sp., Isospora sp. e Trichuris sp. Concluiu-se que existe um risco de contagio para animais e pessoas que frequentam estas praças, indicando a existência de um problema de saúde pública.
\end{abstract}

Palavra-Chaves: Saúde pública. Parasita com potencial zoonótico. Cães.

SUMMARY: In many cities, large canine population circulates freely in the streets and public squares, some of them taken by the owners. In these locations, the dogs can defecate and contaminate the soil with various types and forms of parasites potentially causing zoonoses. Currently there is great concern with regard to these parasites, due to the increasingly close contact of people with their pets. The objective of this study was to verify the occurrence of main intestinal parasites with zoonotic potential in fecal samples of dogs, collected in the public squares from Ituverava-SP, Brazil. We collected 84 samples of fresh feces of dogs in seven public squares from Ituverava-SP, in the period from March to June 2009. As analysis method of the fecal samples was used the technique of WillisMollay (fecal flotation). At total of samples 49 were negative and 35 positive for the presence of helminth eggs, observing a higher incidence of eggs of Ancylostoma sp. (29 samples) and in smaller numbers Toxocara sp. (4 samples) and Dipilidium sp. (2 samples), but not been found in any sample eggs Giardia sp., Isospora sp. and Trichuris sp. It was concluded that there is a risk of contagion to animals and people who frequent these places, indicating the existence of a public health problem.

Keywords: Public health. Parasite with zoonotic potential. Dogs.

\section{INTRODUÇÃO}

A procura por animais de companhia tem aumentado de forma consistente nos últimos anos. A

\footnotetext{
${ }^{1}$ Docente do Curso de Medicina Veterinária da Faculdade Dr. Francisco Maeda (FAFRAM).

2 Média Veterinária

${ }^{3}$ Médico Veterinário, Mestrando da Universidade Estadual Paulista "Julio de Mesquita Filho (UNESP), Campus de Jaboticabal-SP. Autor Correspondente: romeumdsantos@ hotmail.com.
} 
adoção de animais sem que seus futuros proprietários tenham pleno conhecimento de suas necessidades, e consequentemente gastos, aliada a uma criação inadequada, resulta em animais soltos na rua e gestações

indesejadas, o que gera grande número de abandono destes animais em logradouros públicos. Estes animais abandonados além de causar ataques à população comprometem a higiene por urinar e defecar em ruas e praças públicas, contaminando o solo com vários tipos e formas de parasitas potencialmente causadores de zoonoses. A contaminação de praças públicas por fezes de cães constitui um problema de saúde pública, devido à possibilidade de transmissão de zoonoses (GUIMARÃES et al., 2005).

A maioria dos cães nasce com vermes que lhe são transmitidos através da placenta da mãe (o contágio, neste caso, se dá pela circulação sanguínea, e a larva se deposita no fígado do feto, onde permanece até o nascimento do filhote) ou durante a amamentação. Quando um filhote adquire uma verminose, a maior parte vai para o intestino onde os vermes causam um quadro verminótico. Entretanto, algumas destas larvas vão para a musculatura do animal e permanecem por lá longos períodos incubadas. Caso o cão seja macho, possivelmente a larva permanecerá na musculatura e não se desenvolverá; mas se for uma fêmea, quando esta ficar prenhe a alteração hormonal, que ocorre durante a gestação, ativará as larvas e desta forma, contaminará os filhotes diretamente no útero ou através da amamentação. O cão também se contamina de outras formas, como por exemplo, através da ingestão de larvas ou ovos dos vermes, que ficam nas fezes de outro cão contaminado; o verme pode entrar pela pele do animal, através das patas que pisaram em lugares infestados ou ainda, pela ingestão de pulgas contaminadas com fases jovens do verme, quando o cão se coça e automaticamente as engole (FORTES, 2004).

Em uma análise de fezes é possível encontrar vários gêneros de helmintos e protozoários. Estes parasitas possuem grande importância tanto para os animais como para a saúde pública pelo fato de causarem doença, inclusive em humanos (zoonose). Dentre os helmintos, de maior importância, transmitidos por cães podemos citar o Ancylostoma sp. e o Toxocara sp. que em suas formas larvais podem causar respectivamente as doenças conhecidas como Larva Migrans Cutânea ("Bicho Geográfico") e Larva Migrans Visceral. As larvas desses parasitas podem provocar irritações na pele e em órgãos internos como fígado, olhos, entre outros. (CHIEFFI et al., 1976). Além destes dois parasitas há também o risco de contágio por outros helmintos, como Dipylidium sp. e Trichuris sp.; e protozoários de maior importância como Giardia sp. e Isospora sp., ambos de importância para a saúde pública.

O objetivo do presente trabalho foi verificar a ocorrência dos principais parasitas intestinais com potencial zoonótico em amostras fecais de cães, coletadas em praças públicas do município de Ituverava-SP.

\section{MATERIAL E MÉTODOS}

Foram coletadas 84 amostras de fezes frescas em 7 praças públicas no município de Ituverava-SP, durante os meses de março a junho de 2009. Em cada praça foram coletadas 12 amostras sendo realizadas em quatro datas distintas, ou seja, 3 amostras de fezes e com 4 repetições por praça. Para o manuseio destas amostras foram utilizados sacos plásticos para armazenagem, palitos de madeira para a coleta e fita 
adesiva para identificação. Como itens de segurança foram utilizados sapatos fechados, jaleco e luvas descartáveis.

Após a identificação, as amostras foram levadas ao laboratório de análises clínicas do Hospital Veterinário da Faculdade Dr. Francisco Maeda (FAFRAM), onde ficaram armazenadas em geladeira até o momento de sua análise pelo Método de Willis-Mollay (HOFFMAN, 1987). Esta técnica se baseia na propriedade que alguns ovos de helmintos apresentam, de flutuar em superfície de uma solução de densidade elevada.

Para elaboração dos resultados foi confeccionado um banco de dados utilizando Microsoft Excel 2003, sendo esses quantificados pela frequência de ocorrência relativa, em números e em porcentagem.

\section{RESULTADOS E DISCUSSÃO}

No total de amostras fecais analisadas 49 estavam negativas e 35 positivas para presença de ovos de helmintos, observando uma maior incidência de ovos de Ancylostoma sp. (29 amostras) e em menores números ovos de Toxocara sp. (4 amostras) e Dipilidium sp. (2 amostras), não sendo ainda encontrados em nenhuma das amostras ovos de Giárdia sp., Isospora sp. e Trichuris sp. (Tabela 1)

TABELA 1- Número de amostras positivas para cada ovo de parasita, encontrado em fezes de cães colhidas durante os meses de março a junho de 2009 em praças públicas do município de Ituverava-SP.

\begin{tabular}{cccccccc}
\hline \hline \multirow{2}{*}{$\begin{array}{c}\mathrm{N}^{\mathrm{o}} \text { total de } \\
\text { amostras }\end{array}$} & $\begin{array}{c}\mathrm{N}^{\circ} \mathrm{de} \\
\text { amostra }\end{array}$ & $\mathrm{s}$ \\
\cline { 2 - 7 } colhidas & negativa & Ancylostom & Toxocara & Dipylidium & Trichuris & Giárdia & Isospora \\
& $\mathrm{s}$ & a sp & $s p$ & $s p$ & $s p$ & $s p$ & $s p$ \\
\hline 84 & 49 & 29 & 4 & 2 & 0 & 0 & 0 \\
\hline \hline
\end{tabular}

Elaborando os dados em porcentagem pode-se observar um grande número de amostras que não continham ovos de nenhuma espécie pesquisada, já dentre as amostras fecais positivas, destacaram-se a presença de ovos Ancylostoma sp. com aproximadamente 35\% do total, Toxocara sp. com $5 \%$ do total e Dipilidium sp. com $2 \%$ do total, sendo que os demais parasitas pesquisados não foram encontrados em nenhuma das amostras avaliadas (Figura 1). 
FIGURA 1- Frequência de ovos por parasita, em amostras de fezes coletadas em praças públicas do município de Ituverava-SP.

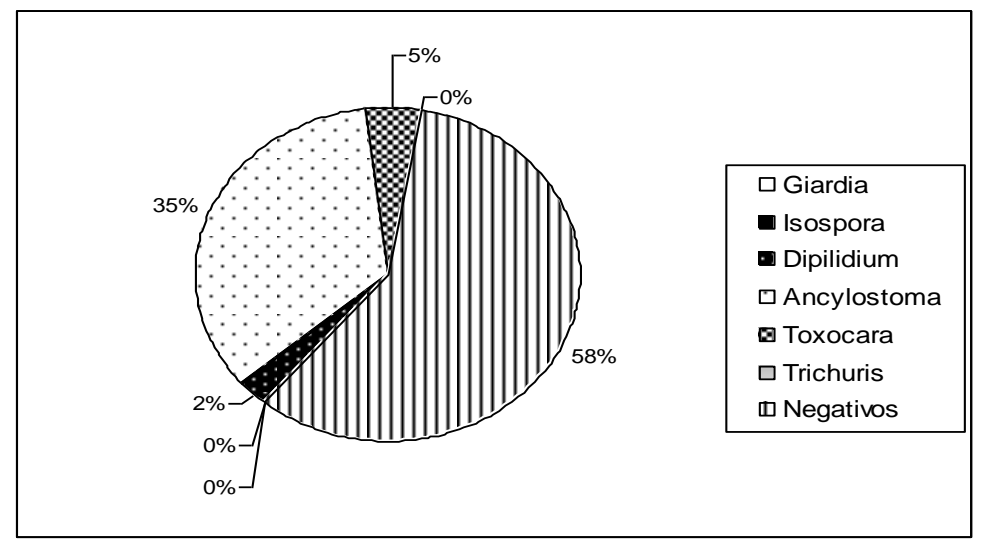

Fonte: Elaborado pelos autores

$\mathrm{Na}$ avaliação da quantidade de amostras positivas, por espécie de parasita em cada uma das 7 praças, houve predomínio de amostras que continham ovos de Ancylostoma sp. em todas as praças, apresentando no mínimo uma amostra positiva em cada praça, já ovos de Toxocara sp. foram observados apenas em amostras na praça 1, 3, 4 e 5; ovos de Dipylidium sp. só foram evidenciados em duas amostras na praça 4 , e como já comentado os ovos dos outros parasitas não foram encontrados em nenhuma amostra (Figura 2).

FIGURA 2- Quantidade de amostras positivas para cada espécie de parasita, pesquisados em sete praças públicas do município de Ituverava-SP.

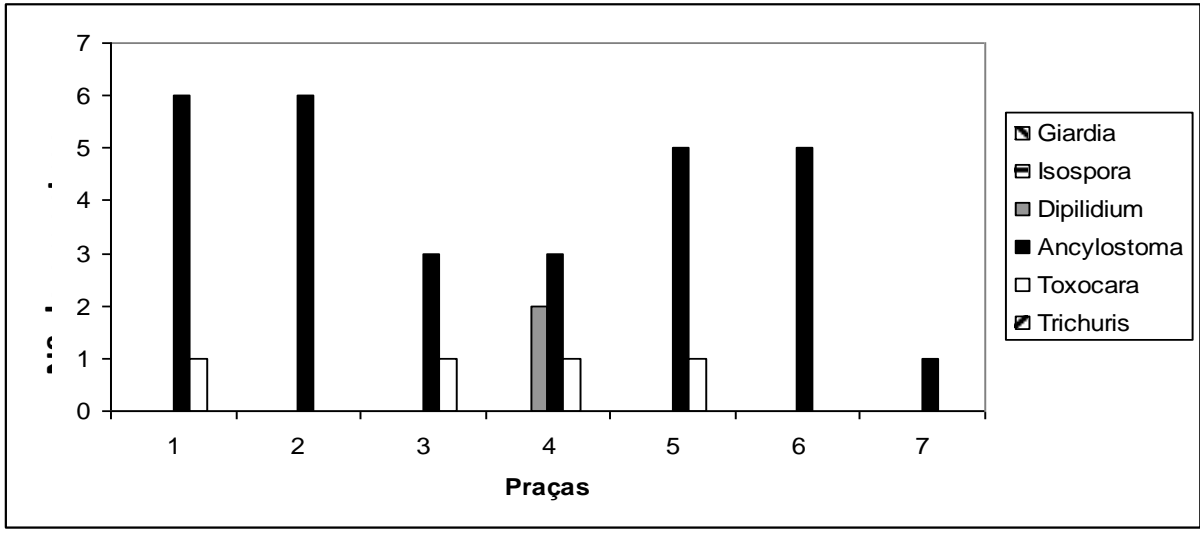

Fonte: Elaborado pelos autores

O predomínio por ovos de Ancylostoma sp. (29/84) em quase todas as amostras fecais foi semelhante aos resultados encontrados por Guimarães et al. (2005) e Rocha et al. (2008), representando assim como o principal helminto registrado em relação aos outros estudados, o que era esperado, pois este é facilmente encontrado parasitando cães e gatos, devido a sua fácil contaminação.

A frequência de ovos de Toxocara sp. (4/84) encontrados nas amostras de fezes neste trabalho foi baixa, concordando com os achados de Castro et al. (2005), que evidenciaram apenas 3 amostras positivas de um total de 257 amostras coletadas, em contrapartida Araújo et al. (1999) e Santarém et al. (1998) encontraram uma maior incidência de ovos deste parasita em amostras de fezes de cães e do solo, 
coletadas em várias praças públicas de Campo Grande, MS, e Botucatu, SP, respectivamente. Segundo Castro et al. (2005) esta discordância possa estar relacionada à elevada resistência ambiental dos ovos de Toxocara sp., que possuem parede espessa protegendo a larva infectante, o que favorece seu acúmulo no solo por longos períodos.

Ovos de Dipylidium sp. foram encontrados em menor incidência nas amostras (2/84), corroborando com os achados de Blazuis et. al. (2005) que relataram apenas 3 amostras positivas de 158 amostras fecais de cães coletadas em logradouros públicos da Cidade de Itapema, SC. Já ovos de Trichuris sp., Giardia sp. e Isospora sp. não foram relatados neste trabalho, se opondo a pesquisa de Cupuano et al. (2006), que em um estudo de contaminação ambiental por ovos e larvas destes helmintos, observaram uma maior frequência de ovos de Trichuris sp. (15,7\%), Giardia sp. (10,2\%) e Isospora sp. (3,3\%), em amostras de fezes coletadas em áreas públicas do município de Ribeirão Preto, SP,

\section{CONCLUSÃO}

Esse trabalho demonstra que existe um risco de contagio para animais e pessoas que frequentam essas praças, especialmente por Ancylostoma sp., sua alta frequência nas amostras, relaciona com a fácil contaminação nos cães, por via percutânea.

O número de amostras negativas encontradas nas fezes analisadas, sugere que alguns cães que frequentam essas praças estão sendo vermifugados por seus proprietários.

A ausência de ovos de Giárdia sp., Isospora sp. e Trichuris sp. nas amostras fecais, pode estar relacionada com o método utilizado, que não é o mais específico para identificação desses endoparasitas.

\section{REFERÊNCIAS}

ARAÚJO, F.R. et al. Contaminação de Praças Públicas de Campo Grande, Mato Grosso do Sul, Brasil, por Ovos de Toxocara e Ancylostoma em fezes de cães. Revista Sociedade Brasileira de Medicina Tropical, v.32, n.5, Uberaba, Set/Out. 1999.

BLAZUIS, R.D. et al. Ocorrência de protozóarios e helmintos em amostras de fezes de cães errantes da cidade de Itapema,Santa Catarina. Revista Sociedade Brasileira de Medicina Tropical, v. 38, n.1, Uberaba, Jan/Fev. 2005.

CAPUANO, D.M.; ROCHA, G.M. Ocorrência de parasitas com potencial zoonótico em fezes de cães coletadas em áreas públicas do municipio de Ribeirão Preto, São paulo, Brasil. Revista Sociedade Brasileira de Epidemiologia, v.9, n.1, São Paulo, Mar. 2006.

CASTRO, J. M.; SANTOS, S. V.; MONTEIRO, N. A. Contaminação de Canteiros de Orla Marítima do Município de Praia Grande, São Paulo, por Ovos de Ancylostoma e Toxoraca em Fezes de Cães. Revista Sociedade Brasileira de Medicina Tropical, v.38, n.2, Uberaba, Mar/Abr. 2005.

CHIEFFI, P.P.; MULLER, E. E. Prevalência de parasitismo por Toxocara canis em cães e presença de ovos de Toxocara sp localidades públicas de zona urbana do município de Londrina, Estado do Paraná, Brasil. Revista Saúde Pública, v.10, n.4, São Paulo, 1976.

FORTES, E. Parasitologia Veterinária. 4. ed. São Paulo: Ícone, 607p, 2004. 
GUIMARÃES, A. M. et al. Ovos de Toxocara sp. E larvas de Ancylostoma sp. em Praças Públicas de Lavras, MG. Revista de Saúde Pública, v.39, n.2, São Paulo, 2005.

HOFFMAN, R. P. Diagnóstico de parasitismo veterinário. Porto Alegre: Sulina, 156p, 1987.

ROCHA, J. R. et al. Incidência do Parasita Ancylostoma sp. no município de Garça-SP. Revista Cientifica Eletrônica de Medicina Veterinária. 2008. Disponível em

$\langle$ http://www.revista.inf.br/veterinaria10/artigos/edic-vi-n10-art07.pdf> $>$. Acessado em 06 jun. 2010.

SANTARÉM, V. A.; SARTOR, I. F.; BERGAMO, F. M. M. Contaminação, por ovos de Toxocara spp., de parques e praças públicas de Botucatu, São Paulo, Brasil. Revista da Sociedade Brasileira de Medicina Tropical, v.31, n. 6, Uberaba, Nov/Dez. 1998. 